\title{
Characterization of pulmonary rehabilitation programs in Canada in 2005
}

\author{
Dina Brooks PhD ${ }^{1,2,4}$, Rebecca Sottana MScPT ${ }^{1}$, Barbara Bell MScPT ${ }^{1}$, Mary Hanna MScPT ${ }^{1}$, \\ Lisanne Laframboise MScPT ${ }^{1}$, Sugi Selvanayagarajah MScPT ${ }^{1}$, Roger Goldstein FRCPC ${ }^{2,3,4}$
}

D Brooks, R Sottana, B Bell, et al. Characterization of pulmonary rehabilitation programs in Canada in 2005. Can Respir J 2007;14(2):87-92.

BACKGROUND: Pulmonary rehabilitation (PR) is recognized as the prevailing standard of care for patients with chronic respiratory conditions. National surveys of PR programs provide important information regarding the structure, content and organization of these programs.

OBJECTIVE: To conduct a national survey to characterize adult PR across Canada, in terms of program distribution, utilization, content and outcome measures.

METHODS: A cross-sectional descriptive study in which questionnaires were mailed to PR programs connected with hospitals or identified through the Canadian Lung Association was performed.

RESULTS: Of the $98 \mathrm{PR}$ programs identified, over $90 \%$ of patients in the programs had chronic obstructive pulmonary disease (COPD) and $57 \%$ of the programs were outpatient. Inpatient programs accounted for only $10 \%$ of the total. The main program components included supervised lower extremity strength (77\%), cycle $(72 \%)$ and treadmill (70\%) training, education (75\%) and breathing retraining (68\%). Over $80 \%$ of patients completed their programs and $90 \%$ of patients were enrolled in a follow-up component. Physical therapists, dieticians, respiratory therapists and respirologists were the most commonly identified health care providers. The most commonly used outcome measures were the $6 \mathrm{~min}$ walk test and disease-specific quality of life questionnaires.

CONCLUSION: There were similarities in program format, content, staffing, follow-up and funding among Canadian PR programs. The marked shortfall between the national PR capacity and the prevalence of COPD meant that only $1.2 \%$ of the COPD population had access to PR.

Key Words: Chronic obstructive pulmonary disease; Prevalence survey; Pulmonary rehabilitation

Chronic obstructive pulmonary disease (COPD) is a leadUing cause of chronic morbidity and mortality worldwide and is a major public health concern (1). In 1999, a written survey administered on behalf of Statistics Canada estimated that more than 750,000 people had been diagnosed with COPD, with a prevalence rate of $2.8 \%$ in men and $3.6 \%$ in women (2). An economic analysis showed that COPD places a significant burden on the Canadian health care system (3).

\section{Caractérisation des programmes de réadapta- tion respiratoire au Canada, en 2005}

\begin{abstract}
CONTEXTE : La réadaptation respiratoire (RR) est considérée comme la norme de soins la plus répandue chez les patients atteints de maladies respiratoires chroniques. Les enquêtes nationales sur les programmes de RR fournissent des renseignements importants sur la structure, le contenu et l'organisation de ces programmes.
\end{abstract}

BUT : L'enquête nationale avait pour but de caractériser la RR pour adultes au Canada en ce qui concerne la répartition des programmes, leur utilisation, leur contenu et les mesures de résultats.

MÉTHODE : Il s'agit d'une étude descriptive, transversale; pour ce faire, des questionnaires ont été envoyés par la poste à des programmes de RR associés à des hôpitaux ou repérés par l'Association pulmonaire du Canada.

RÉSULTATS : Dans les 98 programmes recensés, plus de $90 \%$ des patients étaient atteints d'une bronchopneumopathie chronique obstructive (BPCO) et $57 \%$ des participants étaient des patients externes. Les programmes de réadaptation pour patients hospitalisés ne représentaient que $10 \%$ du total. Les principaux éléments des programmes comprenaient des exercices de renforcement des membres inférieurs (77\%), de l'entraînement sur bicyclette (72 \%) ou sur tapis roulant (70 \%), de l'éducation $(75 \%)$ et de la réadaptation respiratoire (68\%), faits sous surveillance. Plus de $80 \%$ des patients ont terminé leur programme de RR et $90 \%$ des participants ont fait l'objet de suivi. Les fournisseurs de soins indiqués le plus souvent étaient les physiothérapeutes, les diététistes, les inhalothérapeutes et les pneumologues. Pour ce qui est des instruments de mesure, l'épreuve de marche de six minutes et les questionnaires sur la qualité de vie, liée à la maladie arrivaient au premier rang.

CONCLUSIONS : Les différents programmes de RR au Canada présentaient des ressemblances quant à l'organisation, au contenu, au personnel, au suivi et au financement. L'inadéquation entre la capacité d'accueil des programmes de RR à l'échelle du pays et la prévalence des BPCO était telle que seul 1,2 \% de la population visée avait accès à ces programmes.

Pulmonary rehabilitation (PR) is effective for patients with COPD because it results in improved dyspnea, fatigue and mastery (4). It is therefore recommended in many COPD guidelines written on behalf of professional societies $(5,6)$. However, PR is often unavailable because it is poorly funded in many jurisdictions across Canada. A recent national report card issued by the Canadian Lung Association identified that most provinces could do better and that many would fail a

${ }^{1}$ Departments of Physical Therapy; ${ }^{2}$ Graduate Department of Rehabilitation Science; ${ }^{3}$ Medicine, University of Toronto; ${ }^{4}$ West Park HealthCare Centre, Toronto, Ontario

Correspondence: Dr Dina Brooks, Department of Physical Therapy, University of Toronto, 500 University Avenue, Room 160, Toronto, Ontario M5G 1V7. Telephone 416-978-1739, fax 416-978-1539, e-mail dina.brooks@utoronto.ca 
TABLE 1 National distribution of pulmonary rehabilitation (PR) programs

\begin{tabular}{lcc}
\hline Province & $\begin{array}{c}\text { Number of facilities } \\
\text { offering PR programs }\end{array}$ & $\begin{array}{c}\text { Number of } \\
\text { programs offered }\end{array}$ \\
\hline New Brunswick & 2 & 2 \\
Nova Scotia & 2 & 2 \\
Saskatchewan & 2 & 3 \\
Manitoba & 5 & 7 \\
Alberta & 6 & 8 \\
British Columbia & 9 & 14 \\
Quebec & 10 & 21 \\
Ontario & 24 & 41 \\
Total & 60 & 98 \\
\hline
\end{tabular}

standard grading of their approach to the management of individuals with COPD (7).

In 1999, we published the results of the first national survey across Canada, undertaken to provide information regarding the structure, content and organization of PR (8). We noted that this service was often unavailable to those who could potentially benefit from it, with only $0.5 \%$ of patients diagnosed with COPD being able to access the service (9). A subsequent United Kingdom survey noted a similar shortfall and reported that less than $1 \%$ of patients with COPD received PR (9).

Since our first survey, there has been an increase in awareness among both the public and health care providers of the need for PR programs in Canada. We therefore undertook this second national survey to characterize PR programs and to extend our observations to include program completion, readmission and follow-up. We also aimed to estimate the proportion of the Canadian COPD population that has access to PR.

\section{METHODS}

Design

Ethics approval (Protocol \#13238) was obtained from the University of Toronto Research Ethics Board. The study was a cross-sectional descriptive study that involved mailing an updated version of the previous survey (8) across Canada. Between March and April 2005, surveys were sent to provincial hospitals (greater than 250 beds) and rehabilitation centres obtained from the 2004 Canadian Health Facilities Directory (10) as well as to rehabilitation programs identified by the Canadian Lung Association and their provincial offices. French surveys were sent on request. In addition, programs were asked to identify any other programs in their region to provide a cross-check and reduce the likelihood of a program being omitted.

A prenotice letter was sent one week before mailing of the survey, to notify the sites and promote their participation (11). Subsequently, the survey and a prepaid reply envelope were mailed to all facilities. The survey was addressed to the rehabilitation department, requesting that it be directed to the manager of the PR program for completion by the most appropriate health care professional. An acknowledgement or reminder postcard was sent one week after mailing the initial survey, thanking the participants or reminding them to return the information requested. This postcard restated the survey contact information. A second reminder letter was sent two to four weeks later with a replacement survey. This letter emphasized the importance of the project and restated that confidentiality was guaranteed. Participants were offered an instructional video on COPD from the Canadian Lung Association as an incentive to participate in the survey.

\section{Survey instrument}

The survey instrument updated and extended the previous Canadian survey of 1999 (8). Points were added based on a careful review of the PR literature from 1999 to 2005. A 32-item questionnaire was developed (Appendix 1 available at www.pulsus.com) and pretested by a group of physical therapists, experienced in chronic respiratory diseases, who were not currently associated with PR. The purpose of the pretest was to confirm the relevance of the information requested and to estimate the time to completion. After modifications - comprising wording clarifications, question expansion and deletion of less relevant questions the questionnaire was translated into French. The final questionnaire required an estimated $20 \mathrm{~min}$ to complete.

\section{Data analysis}

Descriptive statistics such as the mean, median and range were calculated. The national pulmonary rehabilitation capacity was calculated by summing the program estimates, derived from multiplying the number of patients enrolled in a program by the number of program rotations available in a year (52 weeks divided by the program duration in weeks). For example, a four-week program with eight patients could accommodate 104 patients annually.

\section{RESULTS}

Response rate, program location and types

Of the 244 surveys mailed, 149 (61\%) were returned, from which 60 facilities (40\%) reported having one or more PR programs for a total of 98 programs. The remaining 89 facilities confirmed the absence of a program in their survey response. Only eight provinces indicated that they had PR programs, with none being identified in Prince Edward Island or Newfoundland. No surveys were sent to any of the three territories because they did not meet the requirement for hospital size (greater than 250 beds) and no known programs existed at the time of the study. The distribution of PR facilities is summarized in Table 1.

Most programs (57\%) were located in outpatient settings, with inpatient programs accounting for $10 \%$ and home-based programs for $5 \%$. Maintenance programs accounted for $22 \%$ (Table 2). There were five programs $(5 \%)$ under the category of 'other': three were described as booster, one by individual appointment and one as a research program.

Of the 98 programs, 49 (50\%) enrolled patients on a continuous basis while 41 enrolled patients using a block format (eight no response). Table 2 summarizes the program size, duration and session length. Taken together, the national PR capacity was 8927 individuals per annum.

\section{Diagnostic groupings}

Participants were asked to estimate the percentage of patients in their program with a given diagnosis. Medians and ranges were reported because the values were not normally distributed. COPD was the most frequently identified diagnostic category (90\% inpatient and outpatient) with asthma being the second most represented category, although in less than $5 \%$ of patients. There was considerable variability with respect to other diagnostic categories. For example, patients with thoracic, parenchymal or neuromuscular restriction comprised up to $20 \%$ of the population for some inpatient and outpatient 
TABLE 2

Program characteristics

\begin{tabular}{|c|c|c|c|c|c|c|}
\hline & $\begin{array}{c}\text { Inpatient } \\
(n=10)\end{array}$ & $\begin{array}{l}\text { Outpatient } \\
(n=56)\end{array}$ & $\begin{array}{l}\text { Home program } \\
\qquad(n=5)\end{array}$ & $\begin{array}{l}\text { Maintenance } \\
(n=22)\end{array}$ & $\begin{array}{l}\text { Other* } \\
(n=5)\end{array}$ & $\begin{array}{c}\text { All } \\
(n=98)\end{array}$ \\
\hline Patients $^{\dagger}$ & $8.1 \pm 12$ & $14.4 \pm 15$ & $8.3 \pm 8.5$ & $29.2 \pm 24.1$ & $9.3 \pm 0.6$ & $16.4 \pm 17.4$ \\
\hline Days/week ${ }^{\dagger}$ & $5.5 \pm 1.6$ & $2.2 \pm 0.8$ & $2.0 \pm 1.0$ & $2.2 \pm 1.7$ & $2.3 \pm 1.0$ & $2.6 \pm 1.5$ \\
\hline Hours/session ${ }^{\dagger}$ & $1.8 \pm 1.5$ & $2.1 \pm 1.1$ & $2.0 \pm 1.0$ & $1.5 \pm 0.5$ & $1.6 \pm 0.5$ & $1.9 \pm 1.0$ \\
\hline Duration $^{\dagger}$ (weeks) & $3.9 \pm 2.2$ & $9.1 \pm 5.6$ & $9.0 \pm 2.5$ & $13.3 \pm 5.9$ & $8.3 \pm 4.0$ & $8.9 \pm 5.5$ \\
\hline National rehabilitation capacity $\ddagger$ & 911 & 5101 & 455 & 2004 & 455 & 8927 \\
\hline
\end{tabular}

*Three were described as booster, one as by individual appointment and one as a research program; ${ }^{\dagger}$ Mean and standard deviations; $¥$ The national rehabilitation capacity was calculated by summing the program estimates, derived from multiplying the number of patients enrolled in a program by the number of program rotations available in a year

\section{TABLE 3}

Components of pulmonary rehabilitation

\begin{tabular}{|c|c|c|c|c|c|}
\hline Component & $\begin{array}{c}\text { Inpatient } \\
\text { n (\%) }\end{array}$ & $\begin{array}{c}\text { Outpatient } \\
\text { n (\%) }\end{array}$ & $\begin{array}{c}\text { Home program } \\
\text { n (\%) }\end{array}$ & $\begin{array}{c}\text { Maintenance } \\
\mathbf{n}(\%)\end{array}$ & $\begin{array}{l}\text { Other }^{\star} \\
\text { n (\%) }\end{array}$ \\
\hline Aerobic exercise - walking & $9(90)$ & $27(48)$ & $1(20)$ & $13(59)$ & $2(40)$ \\
\hline Aerobic exercise - cycling & $5(50)$ & $44(79)$ & $2(40)$ & $17(77)$ & $3(60)$ \\
\hline Aerobic exercise - treadmill & $5(50)$ & $47(84)$ & $0(0)$ & $15(68)$ & $2(40)$ \\
\hline Strength training - upper extremity & $6(60)$ & $36(64)$ & $2(40)$ & $17(77)$ & $3(60)$ \\
\hline Strength training - lower extremity & $6(60)$ & $49(88)$ & $2(40)$ & $15(68)$ & $3(60)$ \\
\hline Breathing exercises & $8(80)$ & $42(75)$ & $1(20)$ & $14(64)$ & $2(40)$ \\
\hline Training in activities of daily living & $8(80)$ & $46(82)$ & $2(40)$ & $3(14)$ & $3(60)$ \\
\hline Self-management & $6(60)$ & $34(61)$ & $3(60)$ & $7(32)$ & $3(60)$ \\
\hline Energy conservation & $7(70)$ & $44(79)$ & $2(40)$ & $4(18)$ & $3(60)$ \\
\hline Nutritional support & $7(70)$ & $46(82)$ & $1(20)$ & $4(18)$ & $2(40)$ \\
\hline Inspiratory muscle training & $5(50)$ & $40(71)$ & $1(20)$ & $3(14)$ & $1(20)$ \\
\hline Smoking cessation & $3(30)$ & $14(25)$ & $0(0)$ & $2(9)$ & $2(40)$ \\
\hline Psychosocial support & $7(70)$ & $43(77)$ & $2(40)$ & $5(23)$ & $2(40)$ \\
\hline Home exercise prescription & $8(80)$ & $43(77)$ & $2(40)$ & $4(18)$ & $3(60)$ \\
\hline Education & $8(80)$ & $54(96)$ & $2(40)$ & $6(27)$ & $3(60)$ \\
\hline
\end{tabular}

*Three were described as booster, one as by individual appointment and one as a research program

programs but $0 \%$ for most programs. The percentage of patients with a particular diagnosis was similar between different types of programs. Current smokers were accepted by $45(75 \%)$ of the 60 facilities, of which $13(27 \%)$ required that they participate in a smoking cessation program and $38(78 \%)$ monitored whether they discontinued smoking during the rehabilitation program.

Waiting lists, program completion and readmission Waiting lists for enrollment were identified in 36 (60\%) of PR facilities, with $14 \pm 12$ patients waiting for $11 \pm 9$ weeks. In 35 facilities (59\%), more than $80 \%$ of patients completed PR with only one facility reporting less than $40 \%$ of patients completing. The main reasons for noncompletion related to health issues, especially a respiratory exacerbation ( $85 \%$ of facilities), with program dissatisfaction being reported by seven (12\%) facilities. More than $51(80 \%)$ facilities were prepared to readmit patients for PR although in most instances, fewer than $20 \%$ of patients were re-enrolled.

\section{Program components}

Exercise was the predominant modality, with 75 (77\%) programs including lower extremity strength training, and lower extremity endurance training either by cycling $(72 \%)$ or treadmill $(70 \%)$ training. Breathing exercises were included in $68 \%$ of programs. More than $60 \%$ of programs included upper extremity strength training. Other exercise modalities included training for activities of daily living, energy conservation and a home exercise prescription (Table 3).

Among programs which offered patient education, more than $90 \%$ included the following topics: medication use, signs of infection, energy conservation, pulmonary anatomy and physiology, relaxation and panic control, and nutrition. End of life decision-making, sleep hygiene or advanced care planning were offered in less than $50 \%$ of programs. Family members were invited to participate at nearly all (98\%) facilities, with most being invited to attend educational and exercise sessions. The different components and topics considered in the questionnaire can be found in the Appendix (see Appendix at $<$ www.pulsus.com $>$ ).

\section{Health care professionals}

The distribution of health care professionals is summarized in Table 4. Respirologists, physical therapists, respiratory therapists and pharmacists were the most frequently represented and internists, physiatrists and spiritual leaders the least. In 38 (66\%) facilities, at least one health care professional had completed a respiratory educator program and in 18 facilities, at least one health care professional was currently enrolled in training. Respirologists were the most frequent medical directors (63\%) of facilities, with general practitioners directing 14\% and internists or physiatrists accounted for the remaining $23 \%$. 
TABLE 4

Percentage of health care providers in pulmonary rehabilitation programs

\begin{tabular}{|c|c|c|c|c|c|}
\hline Professional & Inpatient (\%) & Outpatient (\%) & Home program (\%) & Maintenance (\%) & Other* (\%) \\
\hline Dietician & 90 & 94 & 100 & 36 & 40 \\
\hline General practitioner & 80 & 34 & 40 & 23 & 20 \\
\hline Manager/director & 70 & 48 & 60 & 42 & 20 \\
\hline Occupational therapist & 100 & 79 & 40 & 42 & 20 \\
\hline Pharmacist & 80 & 61 & 80 & 37 & 40 \\
\hline Respirologist & 80 & 72 & 60 & 52 & 40 \\
\hline Social worker & 90 & 61 & 80 & 32 & 20 \\
\hline
\end{tabular}

*Three were described as booster, one as by individual appointment and one as a research program

TABLE 5

Outcome measures at the start (S) and end (E) of the program

\begin{tabular}{|c|c|c|c|c|c|c|c|c|c|c|c|}
\hline & & \multicolumn{2}{|c|}{ Inpatient (\%) } & \multicolumn{2}{|c|}{ Outpatient (\%) } & \multicolumn{2}{|c|}{$\begin{array}{c}\text { Home } \\
\text { program (\%) }\end{array}$} & \multicolumn{2}{|c|}{ Maintenance (\%) } & \multicolumn{2}{|c|}{ Other* $(\%)$} \\
\hline \multirow[t]{3}{*}{ Functional exercise capacity } & 6 min walk test & 60 & 60 & 89 & 88 & 80 & 80 & 41 & 32 & 80 & 60 \\
\hline & Shuttle & 10 & 10 & 5 & 4 & 0 & 0 & 0 & 0 & 0 & 0 \\
\hline & Timed up and go & 30 & 30 & 7 & 7 & 40 & 40 & 9 & 9 & 20 & 20 \\
\hline Exercise stress test & Incremental power & 30 & 0 & 43 & 14 & 20 & 0 & 9 & 9 & 20 & 20 \\
\hline \multirow[t]{3}{*}{ Health-related quality of life } & Short Form 36 & 0 & 0 & 18 & 18 & 0 & 0 & 14 & 14 & 20 & 20 \\
\hline & Chronic respiratory questionnaire & 10 & 10 & 54 & 52 & 20 & 20 & 9 & 9 & 20 & 20 \\
\hline & St George respiratory questionnaire & 30 & 30 & 18 & 20 & 20 & 20 & 5 & 5 & 40 & 40 \\
\hline Measures of function & Functional independence measure & 30 & 30 & 2 & 0 & 0 & 0 & 0 & 0 & 0 & 0 \\
\hline
\end{tabular}

${ }^{*}$ Three were described as booster, one as by individual appointment and one as a research program

\section{TABLE 6}

Aftercare components

\begin{tabular}{lccccc}
\hline Follow-up component & Inpatient (\%) & Outpatient (\%) & Home program (\%) & Maintenance (\%) & Other (\%) \\
\hline Reassessment & 60 & 64 & 60 & 36 & 30 \\
Supervised exercise & 20 & 29 & 20 & 20 & 14 \\
Support group & 20 & 30 & 20 & 20 & 20 \\
Telephone support & 20 & 39 & 20 & 20 \\
\hline
\end{tabular}

Patient referral for PR was usually through a respirologist $(88 \%)$ or a general practitioner $(85 \%)$, with other health care professionals such as physical therapists, respiratory therapists and registered nurses being identified in $43 \%$ of programs and patient self-referral occurring in $37 \%$.

Outcome measures

Outcome measures are shown in Table 5. The most frequently used measures were the $6 \mathrm{~min}$ walk test and a disease-specific health-related quality of life questionnaire (chronic respiratory questionnaire or St George's respiratory questionnaire). Some programs used a general questionnaire (Short Form 36). Other measures such as the functional independence measure, the shuttle walk test and the 12 min walk test were less frequently used.
Follow-up

Follow-up was considered an integral part of rehabilitation in $49(82 \%)$ facilities and consisted of reassessment, exercise and support (Table 6). Two facilities did not discharge patients from the program and two followed patients as needed. Eleven facilities provided follow-up at either one month $(n=2)$, three months $(n=3)$, six months $(n=4), 12$ months $(n=1)$ and one unspecified. Seventeen facilities had a graduated follow-up program in which the time between appointments lengthenedfor example three, six and 12 months or one, three and six months (usually up to three visits). Sixteen facilities followed the patients at a set intervals - monthly $(n=3)$, every three months $(n=6)$ and every six months $(n=7)$. The most frequently cited barriers to follow-up were lack of funding in $32(53 \%)$ programs and lack of human resources in $30(50 \%)$ programs. 


\section{DISCUSSION}

The response to this second national survey revealed 60 facilities that offered a total of 98 pulmonary rehabilitation programs. This represents an increase in programs from our previous survey in 1999 (8) in which 36 facilities offered a total of 44 programs. The growth is especially visible in Ontario (23 to 41 programs), Quebec (four to 21 programs) and Alberta (three to eight programs), where most programs are located. Two facilities in New Brunswick offer PR but once again, no facilities were identified in Newfoundland or in Prince Edward Island. Part of the program growth can be accounted for by five home-based programs and 22 maintenance programs, which were either not captured or did not exist at the time of the previous survey.

The survey questionnaire was sent to over four times as many facilities $(n=244)$ than the survey of 1999. Modifications were made to the initial survey instrument to include several new questions and response options. Despite the increased survey distribution and networking through the Canadian Lung Association, it is possible that some programs were missed. It is reasonable to consider that some, if not the majority, of the nonresponders did not offer a program. By limiting our distribution to hospitals with more than 250 beds, we may have excluded smaller facilities or rehabilitation centres. Nevertheless, the survey does provide us with some useful approximations of the situation in Canada.

Typically, PR was offered to outpatients, with an average of 14 patients per program, attending for two days a week, for $2 \mathrm{~h}$ per day over nine weeks. Inpatient programs were understandably shorter in duration (four weeks) but more intense, with activities being offered for five to six days a week, each of $2 \mathrm{~h}$ duration. It was interesting to note that the profile of the five home-based programs was similar to that of institutionally based outpatient programs ie, twice a week for nine weeks. Outpatient capacity was five times greater than inpatient capacity and 10 times greater than the capacity of the home programs. COPD remains the most common diagnostic category although programs clearly serve a wide range of diagnostic groupings including asthma, pulmonary restriction, thoracic restriction, neuromuscular disease, cystic fibrosis and patients undergoing or recovering from thoracic surgery.

The Canadian Thoracic Society guidelines on the management of COPD (5) and the American Thoracic Society statement on PR (6), as well as recommendations from other professional societies (12), suggest that the core of PR programs should include supervised exercise training, educationself-management, psychological and social support in PR programs. These elements were included in most programs surveyed. Upper and lower extremity strength training were included in most programs and cycle, walking or treadmill exercise was available in all. Specific training in activities of daily living was very highly visible and psychosocial support was available in $77 \%$ of outpatient and $70 \%$ of inpatient programs. In our previous survey, we noted that smoking cessation programs were offered by fewer than one-third of PR programs across Canada.

Frequently measured outcomes included exercise capacity and health-related quality of life. The 6 min walk test and occasionally the 12 min walk test was used before and after rehabilitation in $70 \%$ and $90 \%$ of inpatients and outpatients respectively, and a disease-specific measure of health-related quality of life was used in $40 \%$ of inpatient programs, $72 \%$ of outpatient programs and $40 \%$ of home-based programs. While very encouraging, it is the authors' view that all programs should include both the domains of exercise and of health-related quality of life as primary outcome measures in rehabilitation. Neither health care utilization nor longer term survival was included in this survey.

Canadian results do not differ dramatically from similar surveys in the United States (9) and the United Kingdom (13) where the majority of programs are also outpatient based, although very few inpatient programs are available in either of these two jurisdictions. Physical therapists were the most frequently identified team members, being present in $100 \%$ of programs in the United Kingdom, 91\% of programs in Canada and $49 \%$ of programs in the United States. Although respiratory therapists are key participants in North American programs, this specialty is not available in the United Kingdom. Physicians were highly represented in programs in all three countries, as were nurses, occupational therapists and dieticians. The components of education were similar across the three countries with topics such as inhaler use, medications, energy conservation and signs of exacerbation being most frequently identified, and sexuality and travel being least frequently discussed.

Assuming there are 750,000 Canadians with COPD (2), it is estimated that only $1.2 \%$ of the COPD population is being served compared with $0.5 \%$ in 1999 (8). Considering the marked benefits of PR on health-related quality of life and functional exercise capacity (4), such a small improvement over this time period further supports the need for increased availability of PR. An ongoing Canadian trial is examining the effect of a home program on outcomes and may provide options for a more economic way to deliver PR (14).

If we are to reduce the burden of chronic respiratory disease among Canadians, then we will need inexpensive, accessible programs. This includes more community- or home-based programs that offer exercise and self-management. There is a need for follow-up and maintenance to address the diminution of benefit that occurs over the subsequent months after the termination of intense rehabilitation phase. These programs may incorporate different approaches such as longer duration of follow-up, repeat programs or postexacerbation booster programs. The identification of support groups in this survey $(20 \%$ inpatient, 30\% outpatient and 20\% home) and of telephone support (20\% inpatient, 39\% outpatient and 20\% home), although in its early stages, represents an encouraging new development.

\section{CONCLUSION}

A second national survey identified a slight increase in PR programs across Canada. Notwithstanding these additional programs, service availability still falls far short of that required to address the burden of chronic respiratory disease. Innovative approaches will be needed to establish inexpensive community- or home-based programs that promote exercise and self-management. Program components and outcome measures were consistent with recommended guidelines. Given the proven benefits to exercise capacity and health-related quality of life, provision of PR remains a worthwhile challenge. 


\section{REFERENCES}

1. Halbert RJ, Isonaka S, George D, Iqbal A. Interpreting COPD prevalence estimates: What is the true burden of disease? Chest 2003;123:1684-92.

2. Lacasse Y, Brooks D, Goldstein RS. Trends in the epidemiology of COPD in Canada, 1980 to 1995 . COPD and Rehabilitation Committee of the Canadian Thoracic Society. Chest 1999;116:306-13.

3. Chapman KR, Bourbeau J, Rance L. The burden of COPD in Canada: Results from the Confronting COPD survey. Respir Med 2003;97:S23-31.

4. Lacasse Y, Brosseau L, Milne S, et al. Pulmonary rehabilitation for chronic obstructive pulmonary disease (Cochrane Review). In: The Cochrane Library, Issue 4, Chichester, United Kingdom: John Wiley \& Sons, Ltd, 2004

5. O'Donnell DE, Aaron S, Bourbeau J, et al. State of the Art Compendium: Canadian Thoracic Society recommendations for the management of chronic obstructive pulmonary disease. Can Respir J 2004;11:7B-59B.

6. American Thoracic Society. Pulmonary rehabilitation - 1999. Am J Respir Crit Care Med 1999;159:1666-82.

7. The Canadian Lung Association. Chronic Obstructive Pulmonary Disease (COPD): A National Report Card. <http://www.lung.ca/media-medias/news-nouvelles_e.php?id=2> (Version current at October 27, 2006).

8. Brooks D, Lacasse Y, Goldstein RS. Pulmonary rehabilitation programs in Canada: National survey. Can Respir J 1999;6:55-63.

9. Yohannes AM, Connolly MJ. Pulmonary rehabilitation programmes in the UK: A national representative survey. Clin Rehabil 2004;18:444-9.

10. Canadian Medical Association. Canadian Health Facilities Directory. Ontario, Canada: Southam Information Products, 2004.

11. Dillman DA. Mail and Internet Surveys: The Tailored Design Method, 2nd edn. New York: John Wiley \& Sons, Ltd, 2000.

12. Pulmonary rehabilitation: Joint ACCP/AACVPR evidence-based guidelines. ACCP/AACVPR Pulmonary Rehabilitation Guidelines Panel. American College of Chest Physicians. American Association of Cardiovascular and Pulmonary Rehabilitation. Chest 1997;112:1363-96.

13. Bickford LS, Hodgkin JE, McInturff SL. National pulmonary rehabilitation survey. Update. J Cardiopulm Rehabil 1995;15:406-11.

14. Maltais F, Bourbeau J, Lacasse Y, et al. A Canadian, multicentre, randomized clinical trial of home-based pulmonary rehabilitation in chronic obstructive pulmonary disease: Rationale and methods. Can Respir J 2005;12:193-8. 


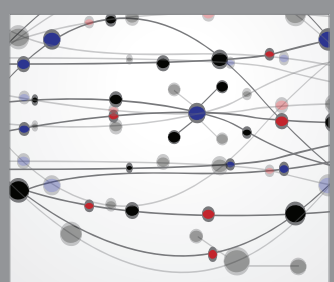

The Scientific World Journal
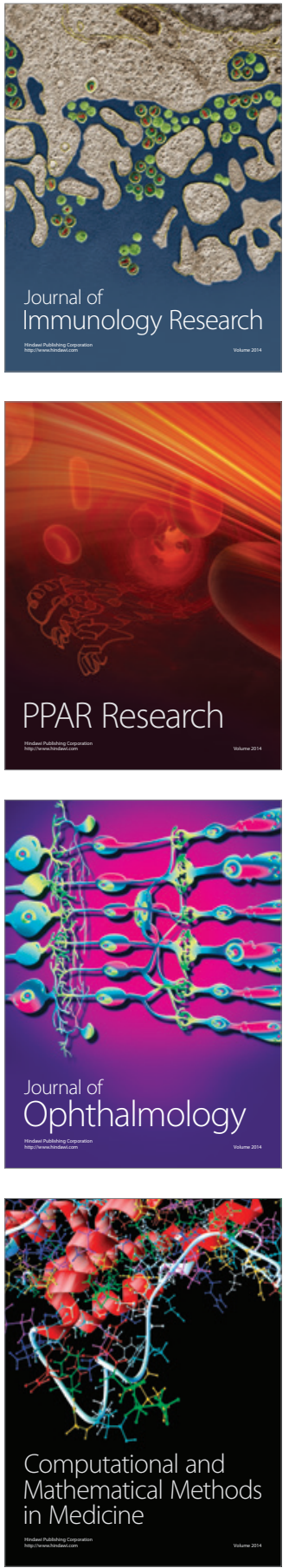

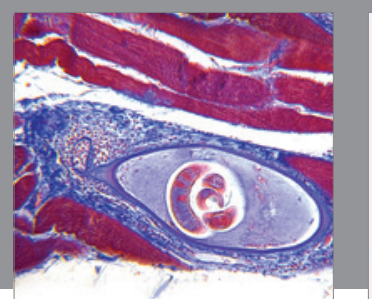

Gastroenterology Research and Practice

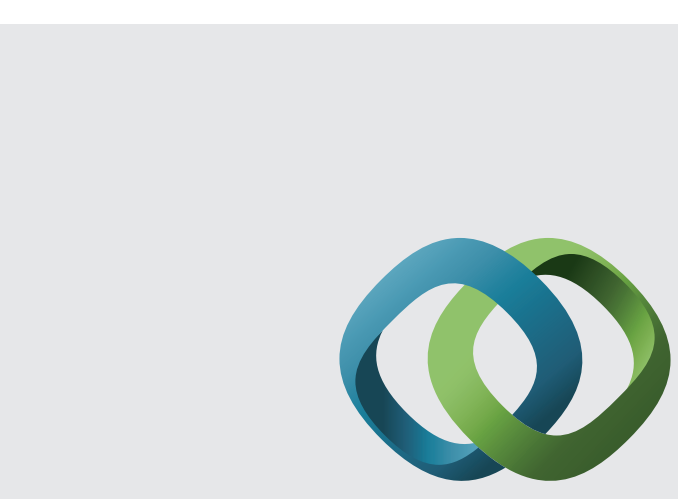

\section{Hindawi}

Submit your manuscripts at

http://www.hindawi.com
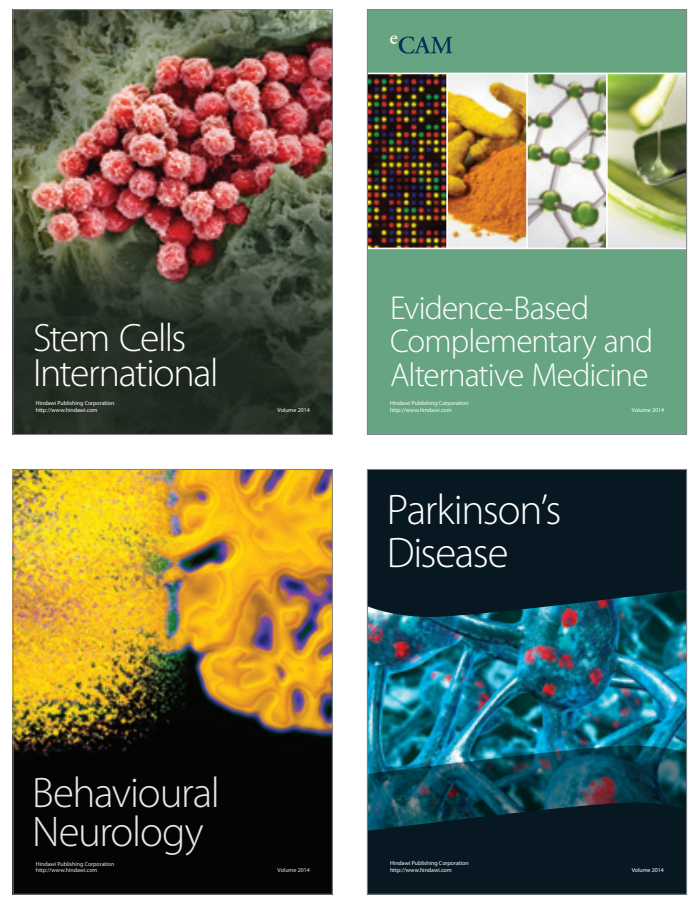
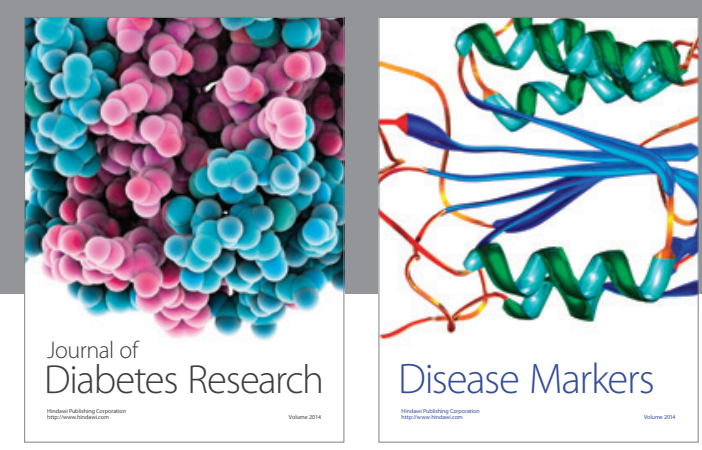

Disease Markers
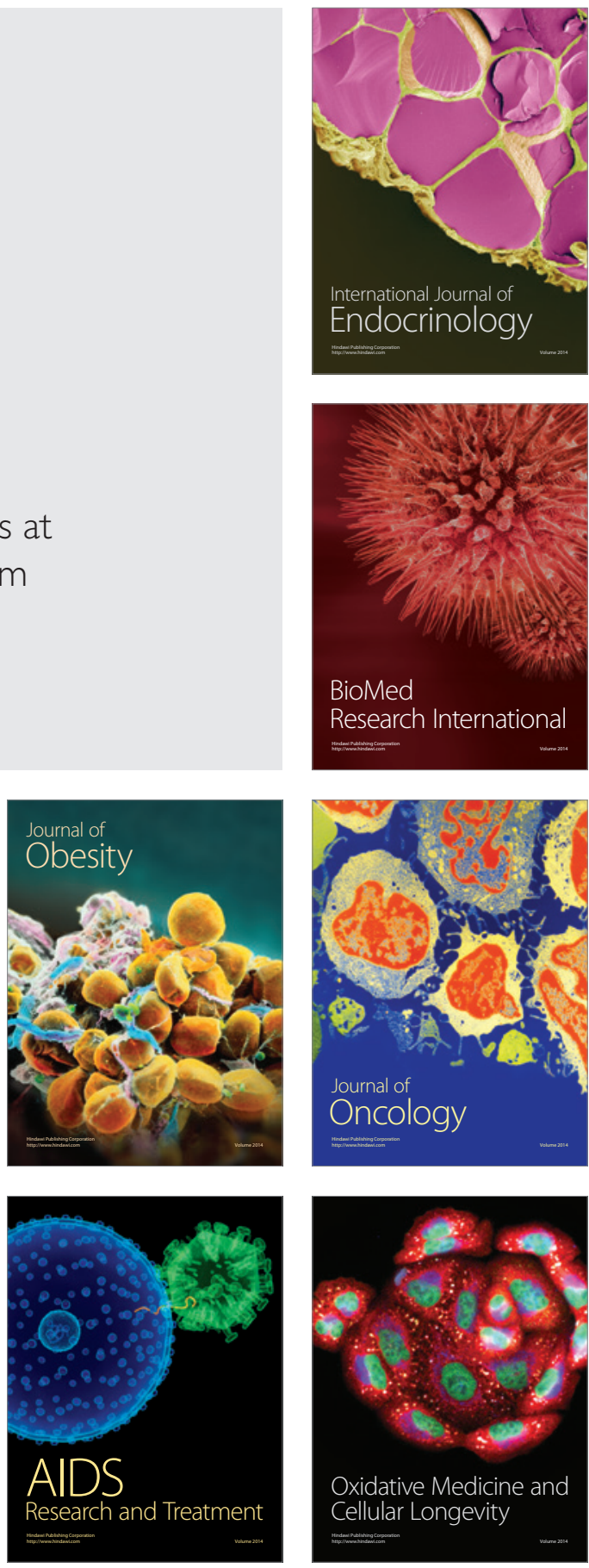